\title{
A comparative study of parental knowledge and adaptation of immigrant youth
}

\author{
Elina Turjanmaa ${ }^{1^{*}}$ (D) and Inga Jasinskaja-Lahti ${ }^{2}$
}

\author{
* Correspondence: elina.turjanmaa@ \\ oulu.fi \\ Elina Turjanmaa, Research Unit for \\ History, Culture and \\ Communications, University of \\ Oulu; Inga Jasinskaja-Lahti, \\ Department of Social Research, \\ University of Helsinki. \\ This study was supported by the \\ Finnish Cultural Foundation \\ (Decision number: 00130515) and \\ conducted at the University of \\ Helsinki. The authors report no \\ conflict of interest. \\ ${ }^{1}$ Research Unit for History, Culture \\ and Communications, University of \\ Oulu, PO Box 1000, Fl-900014 Oulu, \\ Finland \\ Full list of author information is \\ available at the end of the article
}

\begin{abstract}
In general, parental knowledge is known to support adolescents' adaptation. Less is known about the role of parental knowledge in psychological (i.e., anxiety) and socio-cultural (i.e., school achievement) adaptation of adolescents with immigrant background, and how parental knowledge and social characteristics (i.e., gender, generational status, immigrant background, and family' socioeconomic background) of immigrant adolescents jointly influence their adaptation outcomes. This study explores the role of adolescent-reported parental knowledge in explaining adaptation outcomes among first- and second-generation immigrant boys and girls from four different immigrant groups. The study utilizes the national Finnish School Health Promotion survey data ( $N=2697,45 \%$ female, $M$ age $=15.6$ years, $S D=.91$ ) and illustrates the complex relationship between parental knowledge and adolescents' adaptation.
\end{abstract}

Keywords: Parental knowledge, Adolescent adaptation, Immigrant youth, Immigrant paradox

A Comparative Study of Parental Knowledge and Adaptation of Immigrant Youth.

The number of international migrants has grown rapidly in recent years (United Nations 2017). After being traditionally a country of emigration, Finland, following the trajectories of other Nordic countries, has become a country of positive net migration during the last two decades (Statistics Finland 2018a). In Helsinki, the capital of Finland, over $80 \%$ of the second generation are minors (Statistics Finland 2018b). The Finnish education system has gained an international reputation as one of the most successful (Harju-Luukkainen and McElvany 2018), but recent results from PISA assessments (OEDC's Programme for International Student Assessment) indicate that pupils with an immigrant background are falling behind their peers with non-migrant parents whereas the differences between the school performance levels of first- and second-generation immigrants are relatively small (ibid.). Moreover, anxiety symptoms have been found to be higher among immigrant adolescents compared to secondgeneration youth (Halme et al. 2017). The growing number of immigrant children and

(c) The Author(s). 2020, corrected publication 2021. Open Access This article is licensed under a Creative Commons Attribution 4.0 International License, which permits use, sharing, adaptation, distribution and reproduction in any medium or format, as long as you give appropriate credit to the original author(s) and the source, provide a link to the Creative Commons licence, and indicate if changes were made. The images or other third party material in this article are included in the article's Creative Commons licence, unless indicated otherwise in a credit line to the material. If material is not included in the article's Creative Commons licence and your intended use is not permitted by statutory regulation or exceeds the permitted use, you will need to obtain permission directly from the copyright holder. To view a copy of this licence, visit http://creativecommons.org/licenses/by/4.0/. 
the increased ethnic diversity in Finnish society and schools in particular have therefore called for more studies focusing on psychological and school adaptation of adolescents with migrant background (Motti-Stefanidi and Katariina Salmela-Aro 2018). In this study, immigrant adaptation refers to the two areas of psychological well-being and socio-cultural adaptation, including school adaptation that is particularly important in the case of adolescents (Ward 2001).

Previous research comparing adaptation of first- and second-immigrant generation immigrant youth has identified the phenomenon of the immigrant paradox, indicating that first-generation immigrant adolescents are often doing better, both education- and health-wise, than their native-born peers with an immigrant background (García Coll et al. 2012; Strohmeier and Schmitt-Rodermund 2008). Even though the immigrant paradox has sometimes gained contradictory or no support in Europe (Dimitrova et al. 2016; García Coll et al. 2012; Mood et al. 2016; Noam et al. 2014; Sam et al. 2008; Van Geel and Vedder 2011), where it is found, it has largely been explained by family-level factors, such as close-knit family ties and the high achievement orientation of families (Noam et al. 2014), different socialization patterns (Mood et al. 2016), and a supportive family culture (Abebe et al. 2014). Parental knowledge defined as adolescent disclosure is a family-level factor whose relationship with adolescents' adaptation is analyzed in this study. While a large body of research has evidenced that adolescent-reported parental knowledge is an important factor explaining the immigrant paradox in the area of behavioral problems such as substance use (Cristini et al. 2015; Walsh et al. 2014), the role of parental knowledge has been less studied in relation to the educational and health paradox described above. Moreover, studies have shown that the intersectionality of gender and ethnic/ cultural background affects academic achievement (Kim and Calzada 2019) and mental health outcomes (Maleku, 2015; Rask 2018). At the same time, from the perspective of immigrant adolescents' adaptation, girls have been suggested to benefit more from the well-functioning communication with their parents than boys (Walsh and Shulman 2006).

This study examines how first- and second-generation immigrant adolescents' reports of parental knowledge affect their psychological (i.e., anxiety symptoms) and sociocultural (i.e., school achievement) adaptation in Finland. It also examines gender differences in relationship between parental knowledge and adaptation outcomes. The study utilizes the integrative framework on the adaptation of immigrant youth by MottiStefanidi and her colleagues (Motti-Stefanidi et al. 2012). The integrative framework suggests that adolescents' development and acculturation are best understood within and in the intersections of three contexts: societal, interaction, and individual. This study concentrates on the interaction between adolescent-parent communication (i.e., level of interaction) and the social characteristics of the adolescents (i.e., gender, generational status, socioeconomic status, and immigration background). The results show that adolescentreported parental knowledge supports adolescents' adaptation regardless of their immigration background. The findings also suggest that a particular resilience occurs among firstgeneration adolescents with refugee background in the Finnish school context.

\section{Generation, gender, and adolescents' adaptation}

In acculturation psychology studies, immigrant adaptation is typically divided into two areas: psychological and socio-cultural adaptation. Psychological adaptation refers to 
personal well-being (e.g., self-esteem, psychological health), whereas socio-cultural adaptation refers to the acquisition of new social skills, including schooling (Ward 2001). School grades are among the most commonly used indicators of the sociocultural adaptation of immigrant adolescents, whereas internalizing problems, such as anxiety and depression, have been considered crucial indicators of their psychological maladaptation (García Coll et al. 2012). Anxiety and school achievement are used as dependent variables in this study.

As far as the immigrant paradox in psychological and socio-cultural adaptation of immigrant youth is concerned, the findings are mixed. In the U.S., the immigrant paradox has been largely demonstrated among adolescents with Asian and Latino backgrounds when it comes to academic attitudes and behavior, but the results concerning the paradox in school achievement are more complex depending on the dimension (e.g., reading, maths) and the group studied. For example, adolescents with a Cuban background have been found to outperform in maths compared to third- and later generations, whereas adolescents of Mexican origin are performing below the level of their peers (García Coll et al. 2012). Similarly, in Germany, Turkish students, but not students from the former Soviet Union, were found to have higher academic aspirations than their native counterparts (Salikutluk 2016). Evidently, in every context, the school grades of immigrant adolescents vary considerably by age and country of origin, although differences often diminish when parents' socioeconomic background is taken into account (García Coll et al. 2012; Kilpi-Jakonen 2011). Moreover, learning difficulties are associated with a refugee background that often relates to traumatic premigration experiences and interruptions in schooling (Birman and Tran 2017; Fazel et al. 2012). Finally, school achievement is increasingly also a gendered phenomenon: girls tend to achieve better grades at school than boys regardless of the immigration status (Fleischmann et al. 2014; Vaquera and Kao 2012).

With regard to psychological adaptation, it is rather the migration-morbidity hypothesis, proposing that immigrant youth are doing worse than their non-immigrant peers than the immigrant paradox that seems to characterize immigrant youth in Europe (for a review, see Dimitrova et al. 2016). Also, in the Finnish context, it has been found that immigrant adolescents have higher anxiety symptoms compared to second-generation adolescents (Halme et al. 2017). However, as in the case with school adjustment, there is a great variation between immigrant groups concerning the prevalence of psychological problems (Dimitrova et al. 2016; Fazel et al. 2012; Mood et al. 2016; Rask 2018). A comparative study between immigrant and non-immigrant youth in England, Germany, the Netherlands, and Sweden found that immigrant adolescents with a nonEuropean and non-Western background generally report better mental health compared to their native peers (including second generation) (Mood et al. 2016). In Finland, Vietnamese-, Russian-, and Turkish-origin adolescents have been found to report higher levels of anxiety compared to adolescents with a Somali background (Liebkind and Jasinskaja-Lahti 2000). In general, girls are also found to report more internalizing symptoms than boys (Mood et al. 2016).

\section{Parental knowledge and adolescents' adaptation}

In immigrant families, adolescents constantly negotiate with their parents over two tasks: the acculturation and developmental task of adolescence. The increased demands 
of adolescents for independence and identity building supported by their new sociocultural environment are often in conflict with the socialization norms internalized by their parents in a different cultural context. In these negotiations, the quality of adolescent-parent interaction and supportive relationships are important as they eventually support adolescents' positive development and adaptation (Motti-Stefanidi et al. 2012). At the time of adolescence, it is increasingly adolescents' voluntary disclosure that constitutes adolescent-parent communication and parents' possibilities to be aware of their children's daily life (Keijsers et al. 2010; Stattin and Kerr 2000).

Parental knowledge has been identified as an important factor that supports adolescents' adaptation in general (Hamza and Willoughby 2011; Stattin and Kerr 2000) and immigrant youth in particular (Cristini et al. 2015; Walsh et al. 2010; Wang et al. 2012). Parental knowledge about their children's daily activities and whereabout is mainly dependent on adolescent disclosure - rather than the surveillance and monitoring efforts of the parents (Kerr et al. 2010; Stattin and Kerr 2000). Conceptually, thus, our understanding of adolescent-reported parental knowledge equals to adolescent disclosure and is associated with several related factors in adolescent-parent knowledge sharing, such as parental solicitation (Ahmad et al. 2015; Lippold et al. 2013) and parental warmth (Lac et al. 2009; Son and Choi 2013).

In this study, we use the term parental knowledge rather than adolescent disclosure as parental knowledge has been a widely used concept in studies on the relationship between adolescent-reported parental knowledge and different adaptation outcomes. The positive relationship between parental knowledge and immigrant adolescent adaptation has been shown particularly in the domain of externalizing behaviors (e.g., delinquency and substance use) (Cristini et al. 2015; Walsh et al. 2010; Wang et al. 2012). There are some studies showing that immigrant adolescents benefit both psychologically and academically from parental support (Bireda and Pillay 2018; Boonk et al. 2018; Liebkind and Jasinskaja-Lahti 2000; Liebkind et al. 2004), but the role of parental knowledge in predicting the psychological adaptation and school achievement of immigrant adolescents has been neglected.

Importantly, adolescents' have been found to contribute to parental knowledge differently depending on their gender, generational status and cultural background. Girls tend to disclose more than boys (Ahmad et al. 2015) and while closeness in intergenerational relations has been found to associate with more disclosure regardless of migrant background, there are differences in the amount of disclosure between adolescents with different ethno-cultural backgrounds (Yau et al. 2009). There are also cultural differences in how much disclosure between family members is generally expected (Sabatier and Berry 2008). Furthermore, first-generation immigrant adolescents have been found to report lower levels of parental knowledge and more difficulties in talking to parents compared to native-born adolescents (Walsh et al. 2014). On the parents' side, parental monitoring efforts are also dependent on, for example, the intersection of ethnic and socioeconomic status (Suizzo et al. 2014) and adolescents' gender (Suárez-Orozco and Qin 2006). These studies suggest that in order to understand the role of parental knowledge in adaptation among immigrant adolescents, the variety of social and contextual factors intervening in this relationship need to be better acknowledged. As presented below, the integrative perspective on immigrant adaptation offers a framework to take into account this complexity. 


\section{Integrative perspective on adolescents' adaptation}

The integrative framework by Frosso Motti-Stefanidi and her colleagues (Motti-Stefanidi et al. 2012; see also Motti-Stefanidi 2018) builds on developmental, social, and acculturation psychology, and approaches immigrant adolescents' adaptation on three levels: the individual level, the level of interaction and the societal level. The individual level refers to intra-individual characteristics such as personality and motivation. The level of interaction includes all the social environments adolescents interact with, such as family and peer relations. The societal level, in turn, refers to cultural representations and ideologies as well as power positions within society indicated by ethnicity, gender, and socioeconomic status (Motti-Stefanidi et al. 2012). Importantly, the integrative approach argues for the interaction between these different levels when explaining immigrant adaptation (ibid.). Therefore, in this study, immigrant adaptation is examined as a product of the joint effects of their social characteristics and perceived intergenerational relationships.

Finally, this study also acknowledges also another type of interaction characterizing immigrant adaptation, namely the intersectional character of social factors (e.g., gender, cultural and immigrant background) predisposing to different integration outcomes (Viruell-Fuentes et al. 2012). It has been recognized that the simultaneous effects of, for example, gender and immigrant background, account for differences in adaptation (Bauer 2014). In the current study, interaction effects of multiple factors are examined in order to capture the heterogeneity within social categories and to account for the outcomes studied (Bauer 2014; Else-Quest and Hyde 2016; Warner, 2008).

\section{Aims and hypotheses}

This study investigates the relationship between parental knowledge and adolescents' adaptation outcomes (i.e., anxiety and school achievement) in different immigrant groups and the extent to which it depends on adolescents' generational status, gender and family's socioeconomic status (parental educational and employment status). Following prior research, it is anticipated that higher parental knowledge is associated with better school adjustment and less anxiety symptoms among adolescents. Based on previous research conducted in the European context showing that girls typically report higher school achievement but more psychological stress symptoms than boys (Fleischmann et al. 2014; Mood et al. 2016; Vaquera and Kao 2012) and that first generation immigrants suffer more from psychological stress symptoms compared to second generation youth (Dimitrova et al. 2016; Halme et al. 2017), we explore whether the role of parental knowledge in adolescents' adaptation is particularly crucial for girls and firstgeneration youth and in families with lower SES.

\section{Method}

\section{Participants and procedure}

This study utilizes the Finnish School Health Promotion survey data. The survey is carried out every second year in all comprehensive schools, upper secondary schools and vocational education institutions in Finland by the National Institute for Health and Welfare. Thus, the targets of the School Health Promotion Study represent a complete sample of the age group. The study consists of an annually repeated core survey and 
annually changing specific questions. The data of this study has been gathered using classroom-administered questionnaires from comprehensive school pupils (i.e., 8th and 9th graders $^{1}$ ) in April 2013. The rationale to focus on this particular data is that in 2013, the data included a wide-ranging focus on health, well-being, and social relationships among students including those with an immigrant background in Finland (total $N=99,478$ ). The questionnaire included 105 questions. ${ }^{2}$ Pupils had one lesson in which to complete the questionnaire under a teacher's supervision. The study was anonymous and participation was voluntary.

The participants in this study represent adolescents whose both parents were born abroad and who have stayed more than 1 year in Finland ( $N=2697 ; 45 \%$ female). The final sample consists of the first-generation (i.e., those born abroad, $n=1345$ ) and second-generation (i.e., those born in Finland, $n=1352$ ) immigrant adolescents. Adolescents with Finnish born parents are not included in the analysis for two reasons. First, the size of the group $(N=86,065)$ is considerably bigger compared to firstgeneration and second-generation immigrant groups making comparisons difficult. Second, previous research has noted that the comparisons between native and immigrant population often just lead to show the unfavorable position of immigrant adolescents. It may thus be more meaningful to compare immigrant groups to each other and/or first-generation immigrants to second generation youth. The four immigrant/ panethnic groups represent the largest immigrant groups in Finland. The four groups are formed roughly based on the geographical and cultural distance of respondents' countries of origin. The family's refugee background has been found to have an impact on family relationships, anxiety and school failure (for a review, see Fazel et al. 2012), and it is thus important to note that MENA includes countries of origins that are predominantly consisting of those with refugee background (i.e., Somalia and Iraq). The variable of generational status was formed by using the respondents' reports on their and their parents' country of birth. The characteristics of the participants of the study are presented in Table 1.

\section{Measures}

\section{Parental knowledge}

The shortened version of parental knowledge measure (Stattin and Kerr 2000) that includes one item indicating adolescent-parent communication was used to assess parental knowledge (i.e., "Your parents know most of your friends", "Your parents know where you spend your Friday and Saturday evenings", "You can discuss with your parents about your matters"). Respondents rated two of the items on a 3-point scale (e.g., Both do - Only mother/father knows - Neither knows), and one item on a 4-point scale (e.g., Almost never - Sometimes - Quite often - Often). Due to different response options, the first two items were first reversed and then each item was standardized before creating a composite score $(\alpha=.59$ for the whole sample; $\alpha=.57$ for girls; $\alpha=.60$ for boys, $\alpha=.60$ for 1st immigrant generation, $\alpha=.58$ for 2 nd immigrant generation). In order to compare different immigrant groups, the group-based standardized items were used to create an index of parental knowledge for each of the four sub-

\footnotetext{
${ }^{1}$ In Finland, pupils enter 8th grade typically when they are 13 or 14 years old.

${ }^{2}$ The questionnaire can be found online at https://thl.fi/attachments/kouluterveyskysely/Lomakkeet/ ktlomake2013_perus.pdf
} 
Table 1 Descriptive Statistics by Generational Status

\begin{tabular}{|c|c|c|c|}
\hline Characteristic & $\begin{array}{l}\text { All }(N=2697) \\
n(\%)\end{array}$ & $\begin{array}{l}1^{\text {st }} \text { generation } \\
(n=1345), \\
n(\%)\end{array}$ & $\begin{array}{l}2^{\text {nd }} \text { generation } \\
(n=1352), \\
n(\%)\end{array}$ \\
\hline \multicolumn{4}{|l|}{ Gender } \\
\hline Female & $1215(45)$ & $652(49)$ & $563(42)$ \\
\hline Male & $1482(55)$ & $693(51)$ & $789(58)$ \\
\hline \multicolumn{4}{|l|}{ Immigrant background ${ }^{a}$} \\
\hline MENA (Somalia, Iraq) & $766(28)$ & $272(20)$ & $494(37)$ \\
\hline Asians (China, Thailand) & $253(9)$ & $128(10)$ & $125(9)$ \\
\hline Eastern Europeans (Russia, Estonia, FSU) & $1231(46)$ & $761(57)$ & $470(35)$ \\
\hline Western Europeans (Sweden, other Europe) & $447(17)$ & $184(14)$ & $263(20)$ \\
\hline Single parent households & $1030(39)$ & $607(46)$ & $423(32)$ \\
\hline At least one parent unemployed & $1152(43)$ & $615(47)$ & $537(40)$ \\
\hline \multicolumn{4}{|l|}{ Parental education } \\
\hline Neither has higher level education & $1019(50)^{b}$ & $510(51)$ & $509(49)$ \\
\hline Only mother/father has higher level education & $533(26)$ & $253(26)$ & $280(27)$ \\
\hline \multirow[t]{2}{*}{ Both have higher level education } & $473(23)$ & $230(23)$ & $243(24)$ \\
\hline & $M(\mathrm{SD})$ & $M(\mathrm{SD})$ & $M(\mathrm{SD})$ \\
\hline Age, years & $15.59(.91)$ & $15.82(.95)$ & $15.37(.81)$ \\
\hline
\end{tabular}

${ }^{a}$ The response options were: Finland, Sweden, Russia or Former Soviet Union, Estonia, other European country, Somalia, Iraq, China, Thailand, other. Responses in the categories of "Finland" and "other" are not analyzed in this study

${ }^{b}$ Valid percentages. Parental education has high amount of missing values $(n=672,25 \%)$

groups ( $\alpha=.70$ for Asians, $\alpha=.49$ for Eastern Europeans, $\alpha=.65$ for MENA, $\alpha=.51$ for Western Europeans).

\section{Anxiety}

The seven-item generalized anxiety disorder measure (GAD-7) was used to assess problems with the psychological adaptation of adolescents. The respondents were asked to recall how often they have been bothered by specific problems over the last 2 weeks (e.g., "Feeling nervous, anxious, on the edge.", "Worrying too much about different things."). The GAD-7 score was calculated by assigning scores of $0,1,2$, and 3 , to the response categories of 'not at all', 'several days', 'more than half the days', and 'nearly every day', respectively, and adding together the scores for the seven questions. Scores of 5,10 , and 15 were taken as the cut-off points for mild, moderate and severe anxiety, respectively. Cronbach's alpha of the scale was .93.

\section{School achievement}

Self-reported average grades were measured in eight categories $(<6,5 ; 6,5-6,9 ; 7,0-7,4$; $7,5-7,9 ; 8,0-8,4 ; 8,5-8,9 ; 9,0-9,4 ; 9,5-10,0)$ and used to assess socio-cultural adaptation among immigrant adolescents. In the Finnish grading system, 4 indicates fail and 10 excellent.

\section{Social characteristics}

In addition to gender (Male $=-1$, Female $=1$ ), age (in years), immigrant generation (first generation $=-1$, second generation $=1$ ), and immigrant background (Asian, 
Eastern European, MENA, Western European) were asked from the adolescents. Also parental education $(1=$ Neither has a university degree or other higher level of education, 2 = Only the father/mother has a university degree or other higher level of education, 3 = Both have a university degree or other higher level of education), employment status ( $1=$ At least one of the parents unemployed during the current year, $0=$ Other) and family composition ( $1=$ Lives with both parents, $0=$ Other) of adolescents were assessed to be later controlled in the analyses.

\section{Data analyses}

Bivariate correlations were conducted to explore the associations among the main variables. The gender and generational differences in parental knowledge, anxiety, and school grades were tested by using independent samples $t$-tests. In addition, group differences in the main variables between four sub-samples (i.e., Asians, Eastern Europeans, MENA, and Western Europeans) were investigated using one-way analysis of variance (ANOVA) and interpreted in post hoc tests (Tukey's HSD). A univariate analysis of covariance with multiple factors (ANCOVA) was conducted using GLM (general linear model) univariate procedure to test the main effects, and the two-way interaction effects of 1) gender $\mathrm{x}$ parental knowledge, 2) generational status x parental knowledge, and 3) parental education/employment $\mathrm{x}$ parental knowledge on two adaptation outcomes (i.e., anxiety and average school grades) in the whole sample and in the four sub-samples separately. ${ }^{3}$ GLM (rather than the multiple regression approach) was used due to multi-categorical independent variables (i.e., parental education and immigrant background). The main analyses were conducted controlling for the effect of family composition, parental employment status and educational level. Bonferroni correction was used to adjust alpha values in the case of multiple significance tests (Cramer et al. 2016; Shaffer 1995). Due to multiple significance tests, an alpha level of .01 was used in the interpretation of statistically significant results in the GLM models. Statistically significant interaction effects were interpreted using interaction plots and mean level differences between the groups. Analyses were conducted with SPSS 24.

\section{Results}

\section{Descriptive statistics, correlation analysis, and mean comparisons}

Descriptive statistics and correlations of the main variables by immigrant generation are shown in Table 2. Pearson correlations indicated negative associations between parental knowledge and anxiety symptoms and between anxiety symptoms and school grades, while the association between parental knowledge and school grades was positive.

First-generation immigrant adolescents reported higher levels of anxiety symptoms $(M=5.03)$ than second-generation adolescents $(M=4.38), t(2464)=3.00, p=.003$. In contrast, no generational differences were found in school grades $(t(2633)=-1.69$, $p=.091)$ nor in parental knowledge $(t(2647)=-1.18, p=.239)$. In addition, parental knowledge was higher among girls $(M=.08)$ than among boys $(M=-.07, t(2639)=-$

\footnotetext{
${ }^{3}$ The two-way interaction effects on anxiety and school grades were tested in two separate GLM models including 1) the interaction effects of gender $\mathrm{x}$ parental knowledge and generational status $\mathrm{x}$ parental knowledge, and 2) the interaction effects of parental education $x$ parental knowledge and parental employment $x$ parental knowledge.
} 
Table 2 Means, standard deviations and correlations of main variables in the first $(n=1345)$ and second $(n=1352)$ generation

\begin{tabular}{lllllll}
\hline Variables & Mean & SD & Range & $\mathbf{1}$ & $\mathbf{2}$ & $\mathbf{3}$ \\
\hline 1. Parental Knowledge & $-.02 / .01$ & $.75 / .74$ & $-2.06-1.01$ & - & $-.32^{* *}$ & $.16^{* *}$ \\
2. Anxiety & $5.03 / 4.38$ & $5.35 / 5.45$ & $0-21$ & $-.35^{* *}$ & - & $-.08^{* *}$ \\
3. School Achievement & $3.94 / 4.06$ & $1.84 / 1.84$ & $1-8$ & $.14^{* *}$ & $-.07^{*}$ & - \\
\hline
\end{tabular}

Notes: Parental knowledge is a standardized measure. Higher scores in parental knowledge indicate more knowledge. Anxiety range from 0 to 21 (scores of 5, 10 and 15 represent cut-off points for mild, moderate and severe anxiety, respectively). School achievement is a self-reported average grade ranging from 1 to 8 . Correlation coefficients for the first generation are presented below the diagonal, and correlation coefficients for the second generation are presented above the diagonal ${ }^{*} p<.05,{ }^{* *} p<.01$

5.16, $p<.001)$ and girls had more anxiety symptoms $(M=5.55)$ than boys $(M=3.98, t$ $(2464)=-7.28, p<.001)$. School grades varied likewise by gender as girls had better grades $(M=4.34)$ than boys $(M=3.73, t(2633)=-8.56, p<.001)$.

Generational differences in anxiety, school grades and parental knowledge were next investigated in different gender and immigrant groups separately (for the means and standard deviations of the main variables by immigrant background, gender, and generational status see Table 3). Generational differences in anxiety pointed towards gender-specificity as first generation girls $(M=5.85)$ experienced higher levels of anxiety than secondgeneration girls $(M=5.21), t(1134)=2.00, p=.045$, with no differences between the first$(M=4.22)$ and second-generation boys $(M=3.77, t(1328)=1.54, p=.124)$. Instead, in school grades, generational differences were found among boys $\left(M_{1 \text { st generation }}=3.61, M_{2 n d}\right.$ generation $=3.83, t(1446)=-2.33, p=.020)$, but not among girls $\left(M_{1 \text { st generation }}=4.29, M_{2 n d}\right.$ generation $=4.38, t(1185)=-.87, p=.383)$, with second-generation boys having better grades than first-generation boys. There were no generational differences among boys $\left(M_{1 s t \text { generation }}=-.11, M_{2 n d}\right.$ generation $\left.=-.03, t(1452)=-1.83, p=.068\right)$ and girls $\left(M_{1 s t \text { gener- }}\right.$ ation $=.08, M_{2 n d}$ generation $\left.=.08, t(1193)=-.19, p=.849\right)$ in parental knowledge .

When looking at the immigration background, no differences were found between the four immigrant groups in school grades $(F(3,2631)=1.41, p=.237)$, but there were differences in anxiety and parental knowledge. Asian adolescent reported more anxiety symptoms compared to other groups $\left(M_{\text {Asian }}=6.03, M_{\text {Eastern European }}=4.55, M_{M E N A}=\right.$ 4.62, $\left.M_{\text {Western European }}=4.51 ; F(3,2462)=5.25, p=.001\right)$, whereas the level of anxiety symptoms did not differ between the three other groups. Asian adolescents reported the lowest levels of parental knowledge $(M=-.28)$ differing from Eastern Europeans $(M=.04)$, adolescents from MENA countries $(M=-.06)$ and Western Europeans $(M=.13), F(3,2645)=19.13, p<.001$. Parental knowledge in the MENA sample was the second lowest, differing significantly from the other three groups. There were no differences between Eastern and Western Europeans in parental knowledge. Generational differences in school grades and anxiety were only found in the MENA group in the dimension of anxiety $\left(M_{1 \text { st generation }}=5.91, M_{2 \text { nd generation }}=3.94, t(414.64)=4.06, p<.001\right)$.

\section{GLM Univariate analysis: Main effects, two-way interactions, and three-way interactions}

The main effects and two-way interaction effects of parental knowledge and adolescents' social characteristics (i.e., generational status, gender and immigration background) on anxiety scores are presented in Table 4. A significant interaction effect was 
Table 3 Means and standard deviations in the Eastern European $(n=1231)$, Western European $(n=447)$, Asian $(n=253)$ and MENA $(n=766)$ sample

\begin{tabular}{|c|c|c|c|}
\hline & \multicolumn{3}{|l|}{ Mean $(S D)$} \\
\hline & Parental knowledge & Anxiety & School achievement \\
\hline \multicolumn{4}{|l|}{ First Generation } \\
\hline \multicolumn{4}{|l|}{ Asian } \\
\hline Girls $(n=65)$ & $-.02(0.86)$ & $6.59(6.15)$ & $4.28(2.00)$ \\
\hline Boys $(n=63)$ & $-.38(0.95)$ & $5.35(5.28)$ & $3.74(2.10)$ \\
\hline \multicolumn{4}{|l|}{ Eastern European } \\
\hline Girls $(n=396)$ & $.09(.63)$ & $5.60(5.07)$ & $4.23(1.77)$ \\
\hline Boys $(n=365)$ & $-.05(.71)$ & $3.42(4.15)$ & $3.62(1.70)$ \\
\hline \multicolumn{4}{|l|}{ Western European } \\
\hline Girls $(n=87)$ & $.22(.65)$ & $6.17(5.75)$ & $4.59(1.73)$ \\
\hline Boys $(n=97)$ & $.04(0.73)$ & $3.88(4.58)$ & $3.72(1.87)$ \\
\hline \multicolumn{4}{|l|}{ MENA } \\
\hline Girls $(n=104)$ & $-.06(0.88)$ & $6.14(6.71)$ & $4.28(1.95)$ \\
\hline Boys $(n=168)$ & $-.23(0.85)$ & $5.77(6.42)$ & $3.46(1.87)$ \\
\hline \multicolumn{4}{|l|}{ Second Generation } \\
\hline \multicolumn{4}{|l|}{ Asian } \\
\hline Girls $(n=30)$ & $-.24(1.00)$ & $9.43(7.06)$ & $5.10(2.48)$ \\
\hline Boys $(n=95)$ & $-.39(0.92)$ & $5.03(7.16)$ & $4.05(2.24)$ \\
\hline \multicolumn{4}{|l|}{ Eastern European } \\
\hline Girls $(n=215)$ & $.05(.63)$ & $5.76(4.95)$ & $4.51(1.86)$ \\
\hline Boys $(n=255)$ & $.08(.68)$ & $3.35(4.67)$ & $3.82(1.68)$ \\
\hline \multicolumn{4}{|l|}{ Western European } \\
\hline Girls $(n=137)$ & $.20(.53)$ & $4.82(4.41)$ & $4.25(1.70)$ \\
\hline Boys $(n=126)$ & $.05(.72)$ & $3.48(5.02)$ & $3.67(1.77)$ \\
\hline \multicolumn{4}{|l|}{ MENA } \\
\hline Girls $(n=181)$ & $.08(.68)$ & $4.09(5.36)$ & $4.22(1.70)$ \\
\hline Boys $(n=313)$ & $-.05(0.82)$ & $3.85(5.82)$ & $3.83(1.83)$ \\
\hline
\end{tabular}

found between gender $\times$ parental knowledge $(F(1,1718)=7.40, p=.007) .{ }^{4}$ To further explore this interaction effect, parental knowledge was plotted for high $(-1$ SD from the mean) and low (+ 1 SD from the mean) level of parental knowledge. As can be seen in Fig. 1, low parental knowledge was associated with more anxiety symptoms among both boys $(M=9.63, S D=6.70)$ and girls $(M=5.62, S D=6.12)$, but the effect was stronger for girls, $F(1,478)=25.96, p<.001$. In addition, having at least one parent unemployed and being the first generation directly associated with more anxiety symptoms among adolescents, but there were no statistically significant moderation effects of generational status or parental SES on anxiety.

\footnotetext{
${ }^{4}$ The same result was found in the ANCOVA model exploring the same main effect with gender $\times$ parental knowledge as the only interaction term $(F(1,1719)=7.57, p=.006)$. Moreover, the interaction between generational status $\times$ parental knowledge was not detected as significant in the ANCOVA model including the same main effects and only one interaction term (generational status $\times$ parental knowledge $F(1$, 1719) $=0.22, p=.638$ ).
} 
Table 4 Analysis of Covariance (dependent variable: anxiety)

\begin{tabular}{lllllll}
\hline & Sum of Squares & df & Mean Square & $\mathbf{F}$ & $\mathbf{p}$ & $\boldsymbol{\eta \boldsymbol { p } ^ { \mathbf { 2 } }}$ \\
\hline Corrected Model & 6303.38 & 13 & 484.88 & 23.01 & $\mathbf{. 0 0 0}$ & .15 \\
Intercept & 195.03 & 1 & 195.03 & 9.26 & $\mathbf{. 0 0 2}$ & .01 \\
Gender & 2211.70 & 1 & 2122.70 & 100.73 & $\mathbf{. 0 0 0}$ & .06 \\
Lives with two parents & 59.92 & 1 & 59.92 & 2.84 & .297 & .00 \\
Parents' employment status & 409.23 & 1 & 409.23 & 19.42 & $\mathbf{. 0 0 0}$ & .01 \\
Parents' education & 118.54 & 2 & 59.27 & 2.81 & .055 & .00 \\
Immigrant background & 68.42 & 3 & 22.81 & 1.08 & .355 & .00 \\
Generational status & 219.70 & 1 & 219.70 & 10.43 & $\mathbf{. 0 0 1}$ & .01 \\
Parental knowledge & 3033.71 & 1 & 3033.71 & 143.96 & $\mathbf{. 0 0 0}$ & .08 \\
Age & 11.90 & 1 & 11.90 & 0.57 & .453 & .00 \\
Gender $\times$ Parental knowledge & 155.82 & 1 & 155.82 & 7.40 & $\mathbf{. 0 0 7}$ & .00 \\
Generational status $\times$ Parental knowledge & 1.16 & 1 & 1.16 & 0.55 & .815 & .00 \\
Error & $36,204.13$ & 1718 & 21.07 & & & \\
Total & $75,576.00$ & 1732 & & & & \\
Corrected Total & $42,507.51$ & 1731 & & & & \\
\hline
\end{tabular}

${ }^{\mathrm{a}} \mathrm{R}$ Squared $=.15$ (Adjusted $\mathrm{R}$ Squared $=.14$ )

Note: Significant effects are shown in bold

The two-way interactions predicting anxiety were further analysed in the four samples of immigrants separately. The main effect of parental knowledge on anxiety was significant in Eastern European $(F(1,845)=61.91, p<.001)$, MENA $(F(1,395)=35.40$, $p<.001)$ and Western European $(F(1,320)=48.18, p<.001)$ samples, but not in Asian sample $(F(1,128)=2.17, p=.143)$. In addition, there were no main effect of gender $(F$ $(1,128)=3.12, p=.080)$ or generational status $(F(1,128)=0.90, p=.764)$ on anxiety in the Asian sample. Considering that Asian adolescents reported the lowest level of parental knowledge and the highest levels of anxiety reported above, these results suggest that these adolescents are at special risk of psychological maladaptation (cf. Qin 2008). Of three other sub-samples, the main effect of gender on anxiety was found among Eastern Europeans $(F(1,845)=74.26, p<.001)$, MENA youth $(F(1,395)=13.52$, $p<.001)$, and Western Europeans $(F(1,320)=22.85, p<.001)$, and the main effect of generational status on anxiety among adolescents from MENA countries $(F(1,395)=$ $22.55, p<.001)$ and Western Europeans $(F(1,320)=8.58, p=.004)$ but not among Eastern Europeans $(F(1,845)=0.27, p=.603)$. There were no significant interaction effects in any of the four sub-samples. ${ }^{5}$

Next, we tested factors predicting school achievement among immigrant adolescents. The results are presented in Table 5. Being a girl, at a younger age, living with two parents (instead of one), having parents with a higher educational level, and high parental knowledge were related to higher school grades among adolescents. Only generational status was not directly associated with school grades $(F(1,1817)=.75, p=.386)$.

In the ANCOVA model, there were significant interaction effects of gender $\times$ parental knowledge $(F(1,1817)=16.72, p<.001)$ on school grades. The results suggested that high parental knowledge improved school achievement more among girls $(M=$

\footnotetext{
${ }^{5}$ The same results were obtained in the ANCOVA model including three-way interaction effects with gender $\times$ parental knowledge $\times$ immigrant background $(F(1,1709)=1.98, p=.095)$ and with generational status $\times$ parental knowledge $\times$ immigrant background $(F(1,1709)=0.26, p=.901)$.
} 


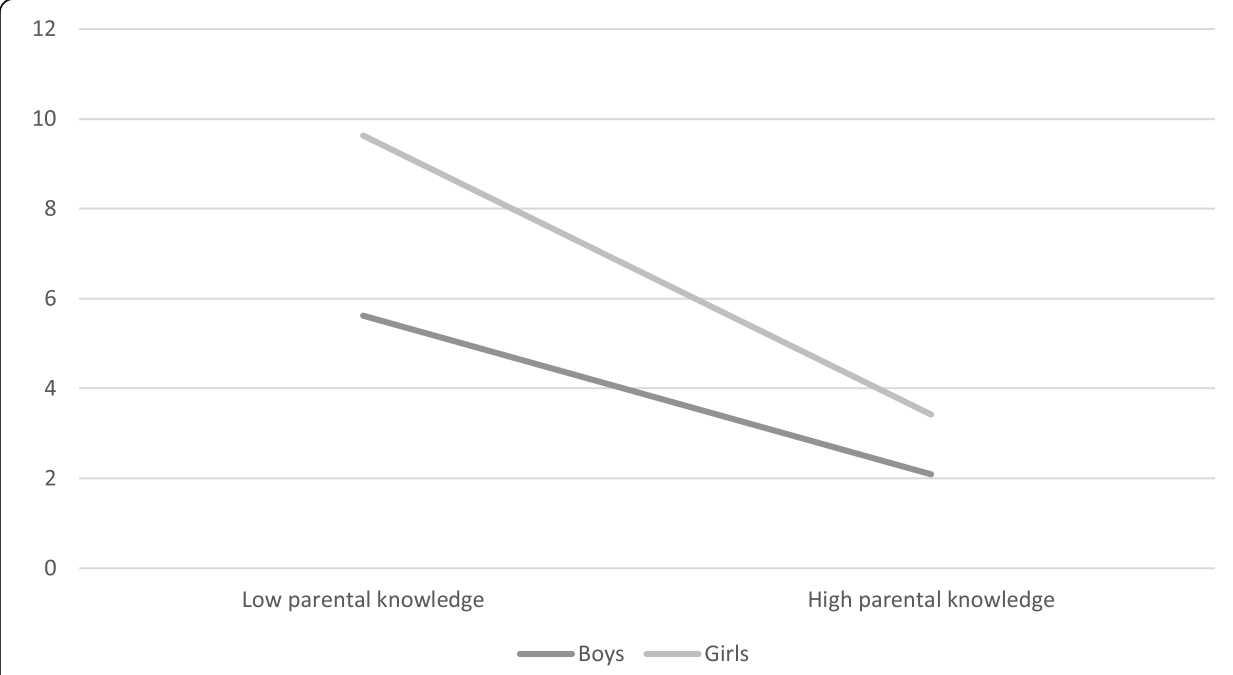

Fig. 1 Interaction between gender and parental knowledge on anxiety

4.87, $S D=1.73)$ than among boys $(M=4.15, S D=1.74), F(1,506)=4.11, p=.043$ (see Fig. 2). There were no differences in the effect of parental knowledge on school grades depending on the generational status or parental educational and employment statuses.

Two-way interaction effects were further explored separately in four sub-groups. The main positive effect of parental knowledge on school grades was found in Eastern $(F(1$, $892)=21.12 p<.001)$ and Western European $(F(1,323)=13.88, p<.001)$ samples, but not in Asian $(F(1,139)=0.18, p=.676)$ and MENA $(F(1,433)=3.31, p=.069)$ samples. The main effect of the gender was detected in Eastern $(F(1,892)=29.44, p<.001)$ and Western European $(F(1,323)=14.95, p<.001)$ samples, but not among the Asians $(F(1,139)=1.48, p=.226)$ and adolescents from MENA countries $(F(1,433)=4.31$, $p=.039)$. As was the case in the whole sample, there was no main effect of the generational status on school grades in any of the sub-samples $\left(F_{\text {Asians }}(1,139)=0.09\right.$, $p=.766 ; F_{\text {Eastern Europeans }}(1,892)=0.10, p=.754 ; F_{\mathrm{MENA}}(1,433)=0.16, p=.693 ; F_{\text {Wes- }}$ tern Europeans $(1,323)=2.56, p=.111)$.

The gendered effect of parental knowledge was detected in the Eastern European sample $(F(1,892)=9.64, p=.002)$ but not in the Asian $(F(1,139)=2.89, p=.091)$, MENA $(F(1,433)=3.50, p=.062)$ or Western European $(F(1,323)=1.06$, $p=.303$ ) samples. $^{6}$ The means of school grades in each sample by gender and (high vs. low) parental knowledge are presented in Fig. 3. In Eastern Europeans, high parental knowledge was related to better school grades among girls $(M=4.97, S D=$ 1.92) than among boys $(M=4.07, S D=1.62)$. As Eastern Europeans represent the biggest sample in our data, it is not surprising that the interaction effect was detected in this sub-sample and not among Asians, MENA and Western Europeans, although the means in each group suggest that a similar pattern of relationships between gender, parental knowledge and school grades could exist in each of the immigrant groups studied.

${ }^{6}$ The same results were found in the ANCOVA model including three-way interaction effects with gender $\times$ parental knowledge $\times$ immigrant background $(F(1,1808)=4.31, p=.002)$ and with generational status $\times$ parental knowledge $\times$ immigrant background $(F(1,1808)=4.78, p=.001)$. 
Table 5 Analysis of covariance (dependent variable: school achievement)

\begin{tabular}{lllllll}
\hline & Sum of Squares & df & Mean Square & $\mathbf{F}$ & $\mathbf{p}$ & $\boldsymbol{\eta p}^{\mathbf{2}}$ \\
\hline Corrected Model & 828.41 & 13 & 63.72 & 22.50 & $\mathbf{. 0 0 0}$ & .14 \\
Intercept & 226.36 & 1 & 226.36 & 79.92 & $\mathbf{. 0 0 0}$ & .04 \\
Gender & 151.05 & 1 & 151.05 & 53.33 & $\mathbf{. 0 0 0}$ & .03 \\
Lives with two parents & 71.11 & 1 & 71.11 & 25.11 & $\mathbf{. 0 0 0}$ & .01 \\
Parents' employment status & .03 & 1 & .03 & .01 & .921 & .00 \\
Parents' education & 314.14 & 2 & 314.14 & 55.46 & $\mathbf{. 0 0 0}$ & .06 \\
Immigrant background & 11.22 & 3 & 3.74 & 1.32 & .266 & .00 \\
Generational status & 2.13 & 1 & 2.13 & .75 & .386 & .00 \\
Parental knowledge & 98.31 & 1 & 98.31 & 34.71 & $\mathbf{. 0 0 0}$ & .02 \\
Age & 34.71 & 1 & 34.71 & 12.25 & $\mathbf{. 0 0 0}$ & .01 \\
Gender $\times$ Parental knowledge & 47.35 & 1 & 47.35 & 16.72 & $\mathbf{. 0 0 0}$ & .01 \\
Generational status $\times$ Parental knowledge & 13.48 & 1 & 13.48 & 4.76 & .029 & .00 \\
Error & 5146.36 & 1817 & 2.83 & & & \\
Total & $37,454.00$ & 1831 & & & & \\
Corrected Total & 5974.77 & 1830 & & & & \\
\hline
\end{tabular}

${ }^{\mathrm{a}} \mathrm{R}$ Squared $=.14$ (Adjusted R Squared $=.13$ )

Note: Significant effects are shown in bold

The interaction effect of generational status and parental knowledge on school grades was significant in MENA $(F(1,433)=11.46, p=.001)$ sample, but not in Asian $(F(1$, $139)=.49, p=.487)$, Eastern European $(F(1,892)=4.69, p=.031)$ and Western European $(F(1,323)=1.21, p=.272)$ samples. As can be seen in Fig. 4 , high parental knowledge is generally associated with the higher school grades of adolescents. However, the effect of high parental knowledge on school grades is somewhat different among firstgeneration adolescents from MENA countries, i.e. youth with a refugee background as their school grades do not improve even if they perceive high parental knowledge $\left(M_{\text {high }}=3.71, S D=1.60, M_{\text {low }}=3.87, S D=2.65\right)$. No significant interaction effects of parental educational / employment status and parental knowledge on school achievement among adolescents was obtained.

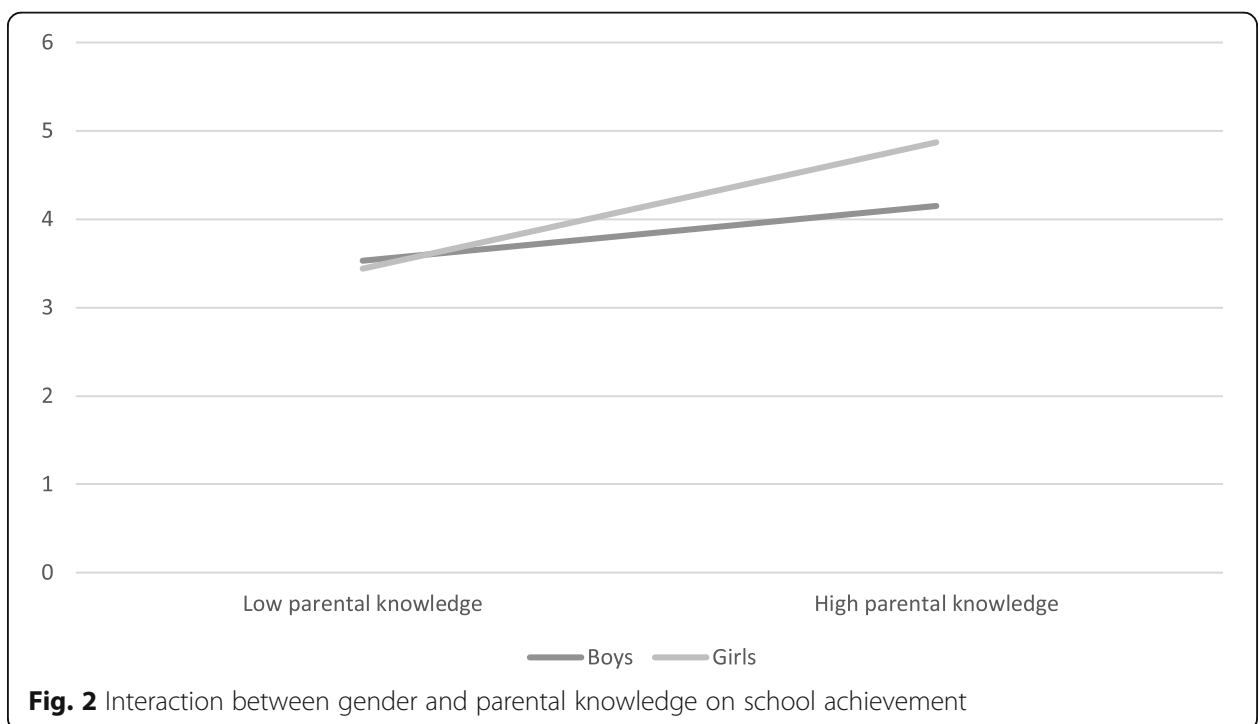




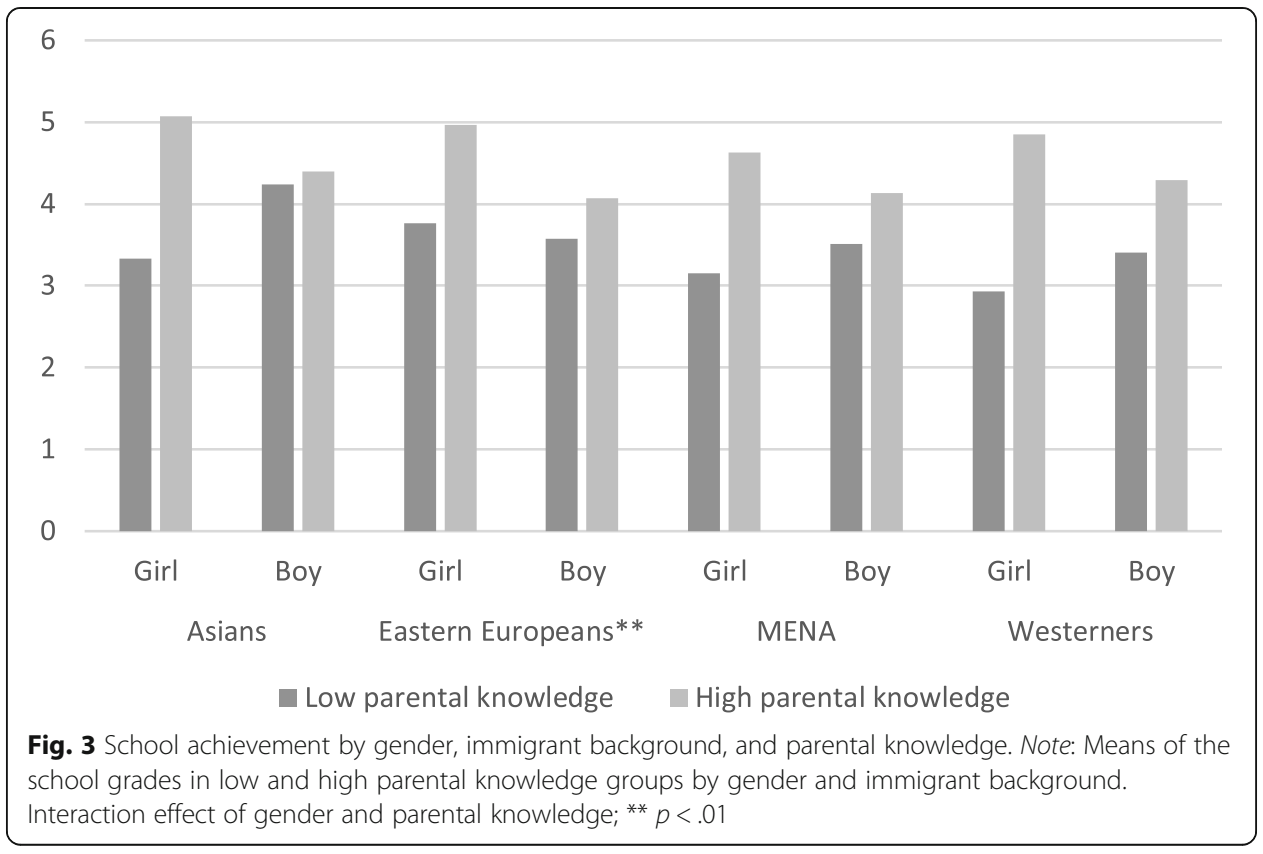

\section{Discussion}

Adolescent-reported parental knowledge has been demonstrated to support adolescents' psychological well-being and school adjustment (Dotterer and Wehrspann 2016; Hamza and Willoughby 2011; Stattin and Kerr 2000). The research has also shown the relationship between parental knowledge and externalizing behaviors among immigrant adolescents (Cristini et al. 2015; Walsh et al. 2014; Wang et al. 2012). However, more research was needed on how parental knowledge is associated with educational and psychological indicators of adaptation. Moreover, studies on the role of parental knowledge where the immigrant paradox occurs were lacking.

In this study, how adolescent-reported parental knowledge is associated with first- and second-generation adolescents' psychological (i.e., anxiety symptoms) and socio-cultural (i.e., school achievement) adaptation was examined. Moreover, interactions between gender and parental knowledge, between generational status and parental knowledge, and between parental SES and parental knowledge on adaptation outcomes were examined in four immigrant groups. Expectedly, higher parental knowledge was related to fewer anxiety symptoms and higher school grades. The data was consistent with the hypotheses of girls' higher school grades and higher levels of anxiety symptoms compared to boys. The hypothesis concerning differences in reported anxiety symptoms between generations was confirmed: First-generation adolescents' anxiety levels were higher compared to secondgeneration adolescents. This finding concerning the whole sample is in line with the prior findings on the health paradox. Importantly, however, previous findings are controversial due to the diversity of the migrant population in Europe (Dimitrova et al. 2016; Mood et al. 2016). Indeed, when the generational differences in the mean levels of anxiety were explored separately in four immigrant groups, the differences were only found in the anxiety levels of the adolescents with a background in MENA countries (i.e., in Somalia and Iraq). 


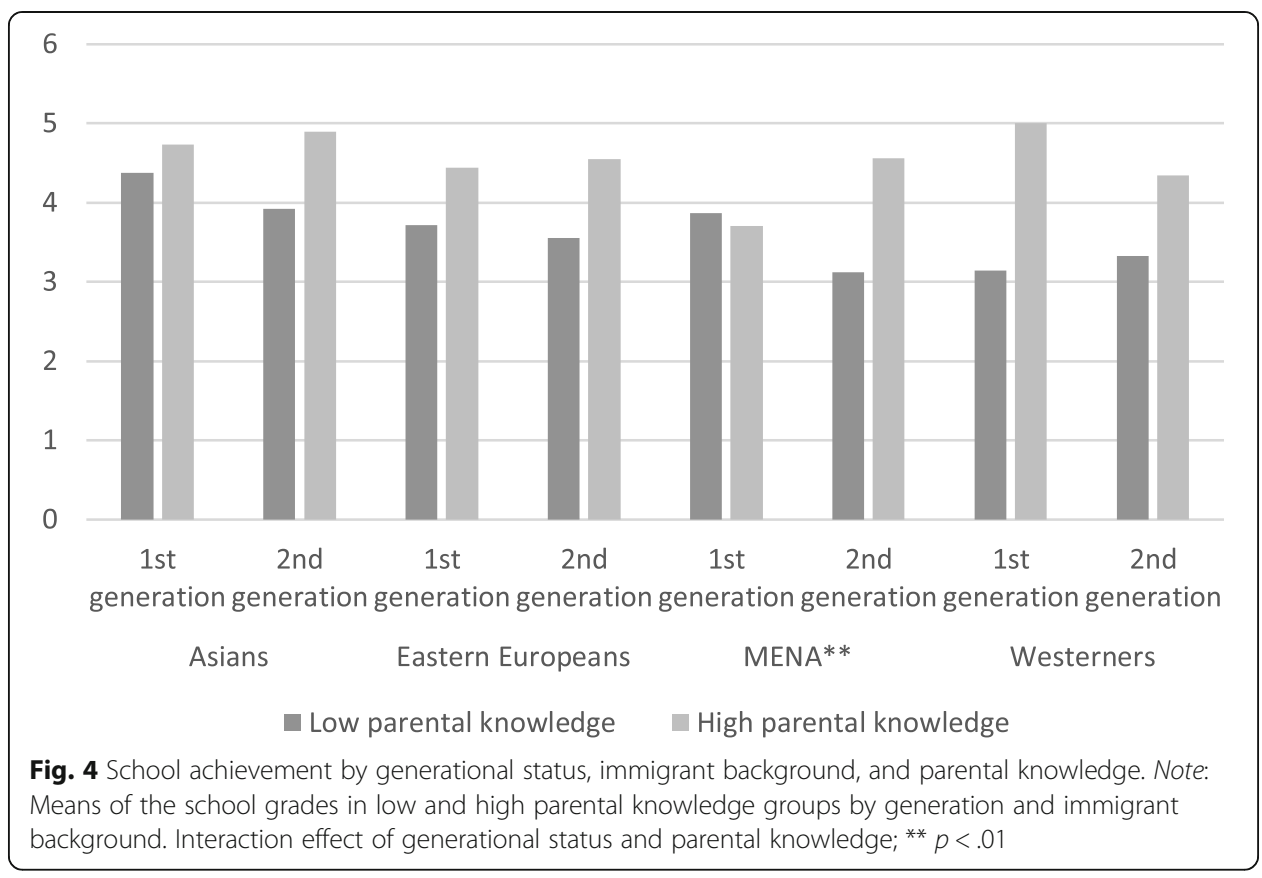

Moreover, the expected generational differences in school grades were not found. Instead, the mean grades of first- and second-generation adolescents did not differ from each other, nor were there differences in the school achievement of the four immigrant groups. At first glance, the immigrant paradox was thus not present in our study, as first-generation immigrants reported higher levels of anxiety than second-generation immigrants and there were no differences in school grades between the two generations. In addition, the relationship between parental knowledge and adaptation outcomes was similar in first- and second-generation immigrants: high parental knowledge was related to lower levels of anxiety and better school grades in both generations. However, as described below, the results pointed to a more complex pattern of relationships explaining adaptation outcomes, including the immigrant paradox, among immigrant adolescents.

First, parental knowledge was somewhat more strongly associated with better adaptation outcomes (i.e., lower levels of anxiety and better school grades) among girls than boys in all four sub-groups of immigrants, although a statistically significant connection between parental knowledge and school grades was only found among the largest subsample, i.e., among adolescents with an Eastern European background. This result supports previous studies that speak for the gendered effect of parental knowledge on the adaptation of immigrant adolescents (e.g., Walsh and Shulman 2006).

Second, while high parental knowledge was related to lower anxiety in all immigrant groups, it explained better school performance among adolescents with Asian and European backgrounds, and among second-generation adolescents from MENA countries. High parental knowledge was thus associated with adolescents' better school grades in the voluntary migrants groups and in all the second-generation groups. In contrast, parental knowledge was less important for the school achievement of the first-generation youth with refugee background (i.e., youth with Somalian or Iraqi background) - a particularly resilient group of adolescents in this study. First-generation 
refugee adolescents with a low level of parental knowledge not only showed as good academic achievement as those with high parental knowledge, but even outperformed their second-generation peers with low parental knowledge. These results may be seen as a sign of the immigrant paradox in a MENA sample and they support previous studies that suggest the resilience of refugee youth. García Coll and Szalacha (2004) found that Cambodian boys in the United States were more likely to do well academically than Portuguese or Dominican boys. Researchers connected Cambodian boys' stronger sense of family obligation to their family's refugee background and the devastating experiences of their families. Forcibly displaced children and youth have a higher likelihood of having experienced trauma, having a disrupted education, and having been separated from primary caregivers (Fazel et al. 2012). Recent studies have stressed that also the immigration process itself and the postmigration experiences, such as prolonged asylum application processes and a lack of social support, may have consequences for adolescents' mental health (Birman and Tran 2008; Fazel et al. 2012). Experiencing such hardships is detrimental not only to mental health (Seglem et al. 2011), but also to learning. Despite all these potential challenges that are beyond the norm, refugee adolescents often do well. This finding has been connected to their desire to pay their parents back (Ceballo et al. 2014) and to improve their status in a society (Salikutluk 2016), as adolescents from other immigrant groups with a higher position in a society might have less motivation when it comes to educational aims.

An alternative interpretation of the insignificance of adolescent disclosure on firstgeneration MENA youth's school achievement is that as the expectations of proper disclosure between family members vary to some extent across cultures (Sabatier and Berry 2008), there may be less disclosure expected among families from Somalia and Iraq compared to the Europeans and Asians in this study. Nondisclosure of adolescents may also be seen as an adaptive strategy that is used in order to increase adolescents' autonomy in relation to their parents (Yau 2016).

Although it undoubtedly exists, the main effect of parental knowledge on both anxiety and school achievement in this study was quite small. It is likely that many other factors related to adolescent-parent communication and overall atmosphere at home, such as parental warmth (Son and Choi 2013; Steinberg 2001) and school-related communication between parents and their children (Boonk et al. 2018), might contribute stronger to adolescents' psychological and socio-cultural adaptation. The supportive role of the school environment has found to be important particularly for immigrant adolescents' psychological adaptation as immigrant parents may have less resources to try to monitor and discuss with their children in a new socio-cultural environment (Walsh et al. 2010). The relationships between parental knowledge and adaptation outcomes were in this study similar regardless of parental education and employment. The intersecting effects of parental education, parental employment, gender, generational status, and immigrant background are, however, complex to analyse. Further studies could concentrate on the complexity of family's socioeconomic background in adolescent-parent communication and adolescents' adaptation more closely.

Research has shown that while immigrant parents often have higher expectations towards their child's achievement compared to native parents, immigrant students receive less emotional support and guidance from their parents than do other students (Villiger et al. 2014). The results of this study supported these views: First- 
generation immigrants (except those from Western European countries) may not need to share information or communicate with their parents concerning their daily activities and schoolgoing in order to achieve in school, whereas parental knowledge was more important for school achievement among second-generation youth.

The study has several limitations. Low Cronbach's alpha (.59 for whole sample) in the 3-item measure of parental knowledge indicates that the reliability of the measure is below ideal, particularly in the sub-samples of adolescents with European background (i.e., Eastern and Western Europeans). Cronbach's alpha is highly affected by the number of items. For example, with the .32 average item intercorrelation in the whole sample, 6 items would result in an alpha level over .70 (Cortina 1993). In the measure consisting of only three items, the received level of alpha can be considered acceptable. However, the results concerning youths with Eastern and Western European backgrounds should be treated with particular caution. The correlations between giving information about one's friends and leisure time and difficulties in adolescent-parent communication seem to be weaker in the European sub-samples than among adolescents with an Asian, Somalian or Iraqi background. Adolescents with a European background may distinguish practical announcements from dialogic, peer-like adolescentparent communication as stricter than their counterparts from Thailand, China, Iraq, and Somalia. In addition, the sizes of the four sub-samples were not equal and the significant interactions appeared particularly among Eastern Europeans who represented the largest group. This has been acknowledged in the results section. Furthermore, this study does not take into account the gendered differences in parental knowledge. Adolescents have been found to favour talking to the mother rather than the father (Smetana et al. 2006), particularly in the case of girls (Ahmad et al. 2015). Further research could explore how adolescent disclosure to mothers and fathers is related to adolescents' socio-cultural and psychological adaptation in the migration context. Another important limitation of the study concerns the absence of classroom-level variables (e.g., immigrant/ ethnic composition of the class) that may have an effect on adolescent-parent communication patterns. In this study, a multilevel approach to the School Health Promotion data was not possible on the level of adolescents' classroom characteristics. The cross-sectional data used in the study does not allow one to make causal claims about the associations between parental knowledge and adaptation outcomes. Therefore, the interpretations of the results are based on previous theorizations and studies on parental knowledge and adolescents' adaptation.

The results of this study show how important it is to acknowledge the interaction of various level factors when explaining immigrant adolescents' adaptation outcomes (see e.g., Motti-Stefanidi et al. 2012). Although the positive relationship between parental knowledge and adolescent adaptation has been confirmed in several studies, family interaction-level factors are often neglected in research on the immigrant paradox (e.g., Dimitrova et al. 2016). This study suggests that the immigrant paradox is two-fold: on the one hand, it describes youth's adaptation from families with a better quality of social interaction, and on the other hand, it describes the potential of youngsters from disadvantaged conditions, such as first-generation refugee youth, to grow, achieve, and seek for a better future, despite the lack of adolescent disclosure and thus opportunities to obtain support from parents. 


\title{
Conclusion
}

This study explored the role of adolescent-reported parental knowledge in the psychological and socio-cultural adaptation of first- and second-generation immigrant adolescents, and of boys and girls, in four immigrant groups. In the analyses, the study addressed a person-context interaction on adolescents' adaptation. The study contributes to literature on adolescent-parent relationships and the acculturation gap by showing how adolescent-reported parental knowledge is generally negatively related to adolescents' anxiety and positively associated with school grades, but has somewhat different effects depending on adolescents' gender, generational status, and immigrant background. Firstgeneration refugees (i.e., adolescents with Somalian or Iraqi background) in the study showed a remarkable resilience. Also, adolescents' expectations on close parental relationships may increase among second-generation youth compared to first-generation immigrant adolescents. The results thus suggest that there might be changes in intergenerational relations in immigrant families towards the Finnish standard in which close and dialogic adolescent-parent relationships are considered ideal (see e.g., Böök and Mykkänen 2019). Further research is needed about the reasons behind the immigrant paradox among adolescents with a refugee background and low parental knowledge.

\section{Acknowledgements}

Not applicable.

\section{Authors' contributions}

ET conceived of the study, participated in its design and coordination and drafted the manuscript. ET and IJ participated in the design and interpretation of the data. ET and IJ participated in the design and coordination of the study and performed the measurement. ET and IJ participated in the design of the study and performed the statistical analysis. The authors read and approved the final manuscript.

\section{Authors' information}

This study is to be included in a doctoral dissertation of the first author.

Funding

This work was supported by the Finnish Cultural Foundation (grant number: 00130515).

\section{Availability of data and materials}

The data that support the findings of this study are available from the Finnish Institute for Health and Welfare but restrictions apply to the availability of these data, which were used under license for the current study, and so are not publicly available. Data are however available from the authors upon reasonable request and with permission of the Finnish Institute for Health and Welfare.

Competing interests

The authors declare that they have no competing interests.

\author{
Author details \\ ${ }^{1}$ Research Unit for History, Culture and Communications, University of Oulu, PO Box 1000, Fl-900014 Oulu, Finland. \\ ¿University of Helsinki, Helsinki, Finland.
}

Received: 6 February 2020 Accepted: 2 October 2020

Published online: 10 December 2020

\section{References}

Abebe, D., Lien, L., \& Hjelde, K. (2014). What we know and don't know about mental health problems among immigrants in Norway. Journal of Immigrant and Minority Health, 16(1), 60-67. https://doi.org/10.1007/s10903-012-9745-9.

Ahmad, I., Smetana, J., \& Klimstra, T. (2015). Maternal monitoring, adolescent disclosure, and adolescent adjustment among Palestinian refugee youth in Jordan. Journal of Research on Adolescence, 25(3), 403-411. https://doi.org/10.1111/jora.12133.

Bauer, G. (2014). In incorporating intersectionality theory into population health research methodology: Challenges and the potential to advance health equity. Social Science \& Medicine, 110(June), 10-17. https://doi.org/10.1016/j.socscimed.2014.03.022.

Bireda, A. D., \& Pillay, J. (2018). Perceived parent-child communication and well-being among Ethiopian adolescents. International Journal of Adolescence and Youth, 23(1), 109-117. https://doi.org/10.1080/02673843.2017.1299016.

Birman, D., \& Tran, N. (2008). Psychological distress and adjustment of Vietnamese refugees in the United States: Associations with pre- and postmigration factors. American Journal of Orthopsychiatry, 78(1), 109-120. https://doi.org/10.1037/00029432.78.1.109. 
Birman, D., \& Tran, N. (2017). When worlds collide: Academic adjustment of Somali bantu students with limited formal education in a U.S. elementary school. International Journal of Intercultural Relations, 60, 132-144. https://doi.org/10.1016/j.jiintrel.2017.06.008.

Böök, M. L., \& Mykkänen, J. (2019). Finnish mothers' and fathers' constructions of and emotions in their daily lives. Scandinavian Journal of Educational Research, 63(3), 412-426. https://doi.org/10.1080/00313831.2017.1376351.

Boonk, L., Gijselaers, H. J. M., Ritzen, H., \& Brand-Gruwel, S. (2018). A review of the relationship between parental involvement indicators and academic achievement. Educational Research Review, 24, 10-30. https://doi.org/10.1016/j.edurev.2018.02.001.

Ceballo, R., Maurizi, L., Suarez, G., \& Aretakis, M. (2014). Gift and sacrifice: Parental involvement in Latino adolescents' education. Cultural Diversity and Ethnic Minority Psychology, 20(1), 116-127. https://doi.org/10.1037/a0033472.

Cortina, J. (1993). What is coefficient alpha?: An examination of theory and applications. Journal of Applied Psychology, 78(1), 98-104. https://doi.org/10.1037/0021-9010.78.1.98.

Cramer, A. O. J., van Ravenzwaaij, D., Matzke, D., Steingroever, H., Wetzels, R., Grasman, R. P. P. P., ... Wagenmakers, E.-J. (2016), Hidden multiplicity in exploratory multiway ANOVA: Prevalence and remedies. Psychological Bulletin and Review, 23(2), 640-647. https://doi.org/10.3758/s13423-015-0913-5.

Cristini, F., Scacchi, L., Perkins, D., Bless, K., \& Vieno, A. (2015). Drug use among immigrant and non-immigrant adolescents: Immigrant paradox, family and peer influences. Journal of Community \& Applied Social Psychology, 25(5), 531-548. https:// doi.org/10.1002/casp.2232.

Dimitrova, R., Chasiotis, A., \& van de Vijver, F. (2016). Adjustment outcomes of immigrant children and youth in Europe: A meta-analysis. European Psychologist, 21(2), 150-162. https://doi.org/10.1027/1016-9040/a000246.

Dotterer, A., \& Wehrspann, E. (2016). Parental knowledge: Examining reporter discrepancies and links to school engagement among middle school studies. Journal of Youth and Adolescence, 45(12), 2431-2443. https://doi.org/10.1007/s10964-016-0550-y.

Else-Quest, N. M., \& Hyde, J. S. (2016). Intersectionality in quantitative psychological research: I. theoretical and epistemological issues. Psychology of Women Quarterly, 40(2), 155-170. https://doi.org/10.1177/0361684316629797.

Fazel, M., Reed, R., Panter-Brick, C., \& Stein, A. (2012). Mental health of displaced and refugee children resettled in highincome countries: Risk and protective factors. Lancet, 379(9812), 266-282. https://doi.org/10.1016/S0140-6736(11)60051-2.

Fleischmann, F., Kristen, C., Heath, A. F., Brinbaum, Y., Deboosere, P., Granato, N., .. Werfhorst, H. G. (2014). Gender inequalities in the education of the second generation in Western countries. Sociology of Education, 87(3), 143-170. https://doi.org/10.1177/0038040714537836.

García Coll, C., Patton, F., Marks, A., Dimitrova, R., Yang, H., Suarez-Aviles, G., \& Batchelor, A. (2012). Understanding the immigrant paradox in youth: Developmental and contextual considerations. In A. S. Masten, K. Liebkind, \& D. Hernandez (Eds.), Realizing the potential of immigrant youth (pp. 238-267). New York: Cambridge University Press.

García Coll, C., \& Szalacha, L. (2004). The multiple contexts of middle childhood. The Future of Children, 14(2), 81-97. https:// doi.org/10.2307/1602795.

Halme, N., Kuusio, H., Kanste, O., Rajala, R., Klemetti, R., \& Seppänen, J. (2017). Ulkomaista syntyperää olevien nuorten hyvinvointi Kouluterveyskyselyssä vuonna 2017 [The well-being of Finnish adolescents with a foreign background in the School Health Promotion study in 2017]. Helsinki: Tutkimuksesta tiiviisti 26, syyskuu 2017. Terveyden ja hyvinvoinnin laitos http://www. julkari.fi/bitstream/handle/10024/135234/URN_ISBN_978-952-302-910-1.pdf?sequence=18isAllowed=y.

Hamza, C., \& Willoughby, T. (2011). Perceived parental monitoring, adolescent disclosure, and adolescent depressive symptoms: A longitudinal examination. Journal of Youth and Adolescence, 40(7), 902-915. https://doi.org/10.1007/s10964-010-9604-8.

Harju-Luukkainen, H., \& McElvany, N. (2018). Immigrant student achievement and education policy in Finland. In L. Volante, D. Klinger, \& O. Bilgili (Eds.), Immigrant student achievement and education policy (pp. 87-102). Cham: Springer. https://doi. org/10.1007/978-3-319-74063-8_6.

Keijsers, L., Branje, S., VanderValk, I., \& Meeus, W. (2010). Reciprocal effects between parental solicitation, parental control, adolescent disclosure, and adolescent delinquency. Journal of Research on Adolescence, 20(1), 88-113. https://doi.org/10. 1111/j.1532-7795.2009.00631.x.

Kerr, M., Stattin, H., \& Burk, W. (2010). A reinterpretation of parental monitoring in longitudinal perspective. Journal of Research on Adolescence, 20(1), 39-64. https://doi.org/10.1111/j.1532-7795.2009.00623.x.

Kilpi-Jakonen, E. (2011). Continuation to upper secondary education in Finland: Children of immigrants and the majority compared. Acta Sociologica, 54(1), 77-106. https://doi.org/10.1177/0001699310392604.

Kim, Y., \& Calzada, E. J. (2019). Skin color and academic achievement in young, Latino children: Impacts across gender and ethnic group. Cultural Diversity and Ethnic Minority Psychology, 25(2), 220-231. https://doi.org/10.1037/cdp0000230.

Lac, A., Alvaro, E., Crano, W., \& Siegel, J. (2009). Pathways from parental knowledge and warmth to adolescent marijuana use: An extension to the theory of planned behavior. Prevention Science, 10(1), 22-32. https://doi.org/10.1007/s11121-008-0111-z.

Liebkind, K., \& Jasinskaja-Lahti, I. (2000). Acculturation and psychological well-being among immigrant adolescents in Finland: A comparative study of adolescents from different cultural backgrounds. Journal of Adolescent Research, 15(4), 446-469. https://doi.org/10.1177/0743558400154002.

Liebkind, K., Jasinskaja-Lahti, I., \& Solheim, E. (2004). Cultural identity, perceived discrimination, and parental support as determinants of immigrants' school adjustment: Vietnamese youth in Finland. Journal of Adolescent Research, 19(6), 635656. https://doi.org/10.1177/0743558404269279.

Lippold, M. A., Greenberg, M. T., \& Collins, L. M. (2013). Parental knowledge and youth risky behavior: A person oriented approach. Journal of Youth and Adolescence, 42(11), 1732-1744. https://doi.org/10.1007/s10964-012-9893-1.

Maleku, A. (2015). The social determinants of immigrant well-being in the United States: A gendered perspective. [Doctoral dissertation, The University of Texas at Arlington]. UTA Libraries. https://rc.library.uta.edu/uta-ir/handle/10106/25391.

Mood, C., Jonsson, J. O., \& Låftman, S. B. (2016). Immigrant integration and youth mental health in four European countries. European Sociological Review, 32(6), 716-729. https://doi.org/10.1093/esr/jcw027.

Motti-Stefanidi, F. (2018). Resilience among immigrant youth: The role of culture, development and acculturation. Developmental Review, 50, 99-109. https://doi.org/10.1016/j.dr.2018.04.002.

Motti-Stefanidi, F., Berry, J., Chryssochoou, X., Sam, D., \& Phinney, J. (2012). Positive immigrant youth adaptation in context: Developmental, acculturation, and socio-psychological perspectives. In A. Masten, K. Liebkind, \& D. Hernandez (Eds.), Realizing the potential of immigrant youth (pp. 117-158). Cambridge: Cambridge University Press.

Motti-Stefanidi, F., \& Katariina Salmela-Aro, K. (2018). Challenges and resources for immigrant youth positive adaptation What does scientific evidence show us? European Psychologist, 23(1), 1-5. https://doi.org/10.1027/1016-9040/a000315. 
Noam, G., Oppedal, B., Idsoe, T., \& Panjwani, N. (2014). Mental health problems and school outcomes among immigrant and nonimmigrant early adolescents in Norway. School Mental Health, 6(4), 279-293. https://doi.org/10.1007/s12310-014-9129-5.

Qin, D. B. (2008). Doing well vs. feeling well: Understanding family dynamics and the psychological adjustment of Chinese immigrant adolescents. Journal of Youth and Adolescence, 37(1), 22-35. https://doi.org/10.1007/s10964-007-9220-4.

Rask, S. (2018). Diversity and health in the population: Findings on Russian, Somali and Kurdish origin populations in. Finland: University of Helsinki.

Sabatier, C., \& Berry, J. W. (2008). The role of family acculturation, parental style, and perceived discrimination in the adaptation of second-generation immigrant youth in France and Canada. European Journal of Developmental Psychology, 5(2), 159-185. https://doi.org/10.1080/17405620701608739.

Salikutluk, Z. (2016). Why do immigrant students aim high? Explaining the aspiration-achievement paradox of immigrants in Germany. European Sociological Review, 32(5), 581-592. https://doi.org/10.1093/esr/jcw004.

Sam, D. L., Vedder, P., Liebkind, K., Neto, F., \& Virta, E. (2008). Immigration, acculturation and the paradox of adaptation in Europe. European Journal of Developmental Psychology, 5(2), 138-158. https://doi.org/10.1080/17405620701563348.

Seglem, K. B., Oppedal, B., \& Raeder, S. (2011). Predictors of depressive symptoms among resettled unaccompanied refugee minors. Scandinavian Journal of Psychology, 52(5), 457-464. https://doi.org/10.1111/j.1467-9450.2011.00883.X.

Shaffer, J. P. (1995). Multiple hypothesis testing. Annual Review of Psychology, 46(1), 561-584. https://doi.org/10.1146/annurev. ps.46.020195.003021.

Smetana, J., Metzger, A., Gettman, D. C., \& Campione-Barr, N. (2006). Disclosure and secrecy in adolescent-parent relationships. Child Development, 77(1), 201-217. https://doi.org/10.1111/j.1467-8624.2006.00865.x.

Son, I. B., \& Choi, J. A. (2013). Parental knowledge trajectory and its relationships with parental warmth and adolescent disclosure for Korean adolescents. Children and Youth Services Review, 35(9), 1643-1649. https://doi.org/10.1016/j. childyouth.2013.06.018.

Statistics Finland (2018a). Preliminary population statistics 2018, July. Retrieved from http://tilastokeskus.fi/til/vamuu/2018/06/ vamuu_2018_06_2018-07-26_tie_001_en.html?ad=notify.

Statistics Finland (2018b). Average age of second generation immigrants with foreign background 11 years. Retrieved from http://www.stat.fi/til/vaerak/2017/02/vaerak_2017_02_2018-06-20_tie_001_en.html\#_ga=2.39874082.1859003202.154383 7039-2122905777.1523593700.

Stattin, H., \& Kerr, M. (2000). Parental monitoring: A reinterpretation. Child Development, 71(49), 1072-1085. https://doi.org/10. 1111/1467-8624.00210.

Steinberg, L. (2001). We know some things: Parent-adolescent relationships in retrospect and prospect. Journal of Research on Adolescence, 11(1), 1-19. https://doi.org/10.1111/1532-7795.00001.

Strohmeier, D., \& Schmitt-Rodermund, E. (2008). Immigrant youth in European countries: The manifold challenges of adaptation. European Journal of Developmental Psychology, 5(2), 129-137. https://doi.org/10.1080/17405620701556953.

Suárez-Orozco, C., \& Qin, D. (2006). Gendered perspectives in psychology: Immigrant origin youth. The International Migration Review, 40(1), 165-198. https://doi.org/10.1111/j.1747-7379.2006.00007.x.

Suizzo, M.-A., Pahlke, E., Yarnell, L., Chen, K.-Y., \& Romero, S. (2014). Home-based parental involvement in young children's learning across U.S. ethnic groups: Cultural models of academic socialization. Journal of Family Issues, 35(2), 254-287. https://doi.org/10.1177/0192513X12465730.

United Nations (2017). International Migration Report 2017. Highlights. New York: United Nations. Retrieved from http://www.un. org/en/development/desa/population/migration/publications/migrationreport/docs/MigrationReport2017_Highlights.pdf.

Van Geel, M., \& Vedder, P. (2011). The role of family obligations and school adjustment in explaining the immigrant paradox. Journal of Youth and Adolescence, 40(2), 187-196. https://doi.org/10.1007/s10964-009-9468-y.

Vaquera, E., \& Kao, G. (2012). Educational achievement of immigrant adolescents in Spain: Do gender and region of origin matter? Child Development, 83(5), 1560-1576. https://doi.org/10.1111/j.1467-8624.2012.01791.x.

Villiger, C., Wandeler, C., \& Niggli, A. (2014). Explaining differences in reading motivation between immigrant and native students: The role of parental involvement. International Journal of Educational Research, 64, 12-25. https://doi.org/10.1016/j.jer.2013.10.004.

Viruell-Fuentes, E. A., Miranda, P. Y., \& Abdulrahim, S. (2012). More than culture: Structural racism, intersectionality theory, and immigrant health. Social Science \& Medicine, 75(12), 2099-2106. https://doi.org/10.1016/.jsocscimed.2011.12.037.

Walsh, S., Djalovski, A., Boniel-Nissim, M., \& Harel-Fisch, Y. (2014). Parental, peer, and school experiences as predictors of alcohol drinking among first and second generation immigrant adolescents in Israel. Drug and Alcohol Dependence, 138(1), 39-47. https://doi.org/10.1016/j.drugalcdep.2014.01.024.

Walsh, S., Harel-Fisch, Y., \& Fogel-Grinvald, H. (2010). Parents, teachers and peer relations as predictors of risk behaviors and mental well-being among immigrant and Israeli born adolescents. Social Science \& Medicine, 70(7), 976-984. https://doi. org/10.1016/j.socscimed.2009.12.010.

Walsh, S., \& Shulman, S. (2006). Gender-related needs, challenges, and dangers in the immigration experience in Israel of emerging adults from the former Soviet Union. Sex Roles, 54, 533-546. https://doi.org/10.1007/s11199-006-9023-1.

Wang, Y., Kim, S., Anderson, E., Chen, A., \& Yan, N. (2012). Parent-child acculturation discrepancy, perceived parental knowledge, peer deviance, and adolescent delinquency in Chinese immigrant families. Journal of Youth and Adolescence, 41(7), 907-919. https://doi.org/10.1007/s10964-011-9705-z.

Ward, C. (2001). The a, B, Cs of acculturation. In D. Matsumoto (Ed.), The handbook of culture and psychology (pp. 411-445). Oxford: Oxford University Press.

Warner, LR. (2008). A Best Practices Guide to Intersectional Approaches in Psychological Research. Sex Roles, 59(5-6), 454-463.

Yau, J. (2016). Adolescent nondisclosure in cultural context: Voices of Chinese American adolescents and parents. Journal of Adolescent Research, 31(5), 606-630. https://doi.org/10.1177/0743558415604218.

Yau, J., Tasopoulos-Chan, M., \& Smetana, J. G. (2009). Disclosure to parents about everyday activities among American adolescents from Mexican, Chinese, and European backgrounds. Child Development, 80(5), 1481-1498. https://doi.org/10. 1111/j.1467-8624.2009.01346.x.

\section{Publisher's Note}

Springer Nature remains neutral with regard to jurisdictional claims in published maps and institutional affiliations. 